\title{
Assaltantes a bordo: violência, insegurança e saúde no trabalho em transporte coletivo de Salvador, Bahia, Brasil
}

\author{
Robbers on board: exposure to violence, \\ insecurity, and other health hazards among \\ mass transportation workers and passengers \\ in Salvador, Bahia, Brazil
}

Eduardo Paes-Machado 1

Charles Levenstein 2

\footnotetext{
1 Instituto de Saúde Coletiva da Universidade Federal da Bahia. Rua Padre Feijó 29, 4o andar, Salvador, $B A$ 40110-170, Brasil. epm@ufba.br 2 Department of Work Environment, University of Massachusetts. One University Avenue, Lowell, MA 01854-2867, U.S.A.
}

\begin{abstract}
This paper examines the impact of violent crime on working conditions, health, and security for bus drivers and ticket takers in the mass transportation system in Salvador, Bahia, Brazil. The research included 195 interviews with workers, labor union officials, passengers, management, and police. In the last ten years there have been 20,572 robberies in a fleet of 2,400 buses operated by 10,151 workers, with 67 deaths and more than US\$500,000 in company losses. Perpetrators are typically poor, unemployed youths, the majority of whom first offenders, seeking easy money primarily for leisure pursuits. The average "take" from such robberies is minimal. The authors observed a pattern of bus robberies as a psychological power game which, for bus workers, apart from physical injuries and fatalities, generates fear, identity conflicts, tense relations with passengers, and labor conflicts involving the recovery of stolen fares and worker and passenger security issues. The article also outlines and evaluates the efficiency of security measures including the use of lethal force by police.
\end{abstract}

Key words Crime; Transportation; Violence; Occupational Health

Resumo O artigo examina o impacto da criminalidade violenta sobre as condições de trabalho, saúde e segurança de trabalhadores, sem deixar de mencionar a situação dos usuários, do transporte coletivo de Salvador, Brasil. A investigação foi feita com base em entrevistas realizadas com 195 pessoas, entre elas trabalhadores, empresários, sindicalistas, agentes de fiscalização da frota de ônibus e policiais. Nos últimos dez anos, numa frota de 2.400 ônibus, operada por 10.151 rodoviários, ocorreram 20.572 assaltos, com morte de 67 pessoas e prejuízo computado de mais de um milhão de reais somente para as empresas. O perfil social típico dos agressores é de jovens pobres e desempregados, muitos sem antecedentes policiais, que buscam dinheiro rápido para atividades de lazer, principalmente. Analisou-se o assalto como um encontro perigoso que, além de lesões fatais e não fatais, produz medo, conflitos de identidade, tensões com os passageiros e conflitos trabalhistas referentes ao pagamento dos prejuízos. Foi avaliada também a eficiência das medidas de segurança policial, incluindo o emprego da força letal, mostrando-se a necessidade de medidas mais amplas, de curto, médio e longo prazo, para controlar a violência nos ambientes de trabalho.

Palavras-chave Crime; Transportes; Violência; Saúde Ocupacional 


\section{Introdução}

O objetivo deste artigo é discutir a violência no local de trabalho, enfocando as agressões de usuários, comuns e delinqüentes, contra os operadores do transporte coletivo e suas conseqüências para as atividades e segurança destes.

A preocupação com o tema decorre tanto da importância dos meios de transporte para a qualidade de vida urbana, como das suas vinculações com o campo de estudo das agressões no ambiente de trabalho. Diferente da noção de agressão não intencional no trabalho, associada, por exemplo, com os acidentes, a violência aqui analisada envolve as ações e reações de vítimas e perpetradores.

Essas agressões podem ser cometidas seja por colegas de trabalho, superiores, iguais ou inferiores hierárquicos, seja por pessoas externas às organizações, o público formado pelos clientes ou consumidores. Podendo ser reportados a uma matriz geral de privação relativa e aumento da violência difusa na sociedade, esses dois tipos de agressão estão inter-relacionados, porém exigem estratégias de análise distintas: uma mais voltada para a hierarquia interna, outra ligada às interações dos trabalhadores das empresas com os clientes.

Com respeito às agressões ligadas ao público, o seu crescimento estaria ligado ao crescimento da economia de serviços no capitalismo atual, indicando os efeitos contraditórios dessa expansão sobre as atividades dos trabalhadores (Neuman \& Baron, 1998; NIOSH/CIB, 1996; Tavares-dos-Santos, 1999). A questão aqui colocada remete para a diferença entre atividades econômicas nas quais os trabalhadores, no exercício das suas atividades, mantêm e não mantêm contato direto com o público. Tal diferença está na base da organização de ambientes diferenciados de trabalho no que diz respeito ao seu grau de "interatividade" com o público.

De modo geral, enquanto nas atividades industriais passou a predominar, desde a Revolução Industrial, o confinamento dos produtores diretos em espaços fabris relativamente isolados ou restritivos à circulação de trabalhadores ou de terceiros, no setor de serviços essa situação nunca se concretizou. É assim que, apesar das fortes variações existentes na natureza, grau de capitalização e tipo de interação com os clientes, o padrão dominante nesse último setor é a relação direta com o público, com toda a incerteza que disso deriva para os prestadores diretos de serviços em termos de demandas e pressões dos consumidores.

Do ponto de vista da psicologia do trabalhador, podem ser rapidamente lembrados os efeitos dos dois ambientes de trabalho. Nos ambientes fechados, a limitação da sociabilidade do trabalhador produz sensações de isolamento e impotência, criando um terreno propício para o despotismo patronal expressado através de agressões morais e psicológicas contra os empregados. Em compensação, essa arquitetura fechada fornece um inegável sistema de proteção, contra atos hostis e agressões de terceiros.

Nos ambientes de trabalho "abertos", por sua vez, o contato com o público por meio da prestação de serviços (e venda de bens) diminui a monotonia, mas exige maior esforço psíquico dos trabalhadores para concatenar atividades técnicas repetitivas com as demandas variadas dos clientes. Por exemplo, no seu famoso estudo etnográfico sobre operadores do transporte coletivo da cidade americana de São Francisco, Belkic \& Schnall (1998) apontaram a violência como o principal estressor dos rodoviários.

Essas agressões, entretanto, seriam mais freqüentes contra trabalhadores que mexem com dinheiro, sob a forma de cobrança de pagamento e arrecadação de tarifas (Neuman \& Baron, 1998; NIOSH/CIB, 1996), e entrega de mercadorias, que trabalham sozinhos, em turnos da noite ou se deslocando, e em áreas de alta criminalidade (NIOSH/CIB, 1996).

Tratando de agressões contra rodoviários do transporte escolar gratuito norte-americano, o estudo de J. T. Sykes (comunicação pessoal) busca contribuir para a melhoria da segurança ocupacional nos veículos coletivos, discutindo tipos de agressão e motivações - materiais, psicológicos e normativos - de adolescentes agressores, oriundos de minorias étnicas contra motoristas brancos.

$\mathrm{Na}$ literatura brasileira sobre o transporte coletivo, Siqueira et al. (1995) discutiram as características da gestão desse tipo de transporte que favorecem conflitos entre operadores e usuários. Os autores vêem os rodoviários como uma categoria que faz um trabalho penoso e altamente regulamentado, mas desfruta de fato de uma autonomia construída, em parte, no desrespeito aos direitos dos usuários. Nesse sentido, os autores subestimaram o contra- poder dos usuários, comuns ou "especiais" (infratores), para desacatar normas, levar vantagens e agredir os trabalhadores.

Abordando os efeitos dos assaltos sobre o psiquismo dos trabalhadores, França et al. (1988) estudaram 144 cobradores de uma empresa de transporte de Salvador, terceira cidade do País nessas ocorrências (Tabela 1). Verificando que quase todos já haviam sido assaltados no trabalho, o estudo encontrou uma alta 
prevalência de estresse ocupacional. Assim, enquanto $37,2 \%$ se sentiam nervosos, tensos ou preocupados, $30,3 \%$ se assustavam com facilidade (França et al., 1988). Por conta da metodologia empregada, o estudo chegou à conclusão equivocada de que esses eventos não se diferenciam de outros estressores, como atenção com o troco, conflitos com usuários, falta de autonomia sobre o trabalho, pausas insuficientes e outros.

Combinando contribuições da criminologia e da saúde coletiva, o presente estudo defende a hipótese de que a violência no trabalho observada no transporte coletivo dificulta o esforço do trabalhador, intensificando a pressão psicológica, complicando a identificação com o trabalho e criando uma dinâmica perversa, cujo combate demanda medidas de curto, médio e longo alcance.

Para desenvolver esse estudo, foram realizadas 195 entrevistas semi-estruturadas, compreendendo 130 rodoviários, cinqüenta passageiros, nove representantes de empresas, dois diretores do sindicato patronal e dois dos trabalhadores e, por fim, dois policiais responsáveis pela operação de combate aos assaltos. Os rodoviários, incluindo motoristas, cobradores e controladores de tráfego, foram escolhidos em paradas de linhas de ônibus com diferentes graus de incidência de crimes. Essas linhas estão distribuídas ao longo das três áreas da região metropolitana de Salvador, uma cidade localizada na entrada de uma grande baía, a Baía de Todos os Santos. As áreas são: Baía (a área dos velhos e novos bairros pobres, a qual circunda a Baía de Todos os Santos); Orla (a área dos novos e ricos bairros da costa oceânica) e Miolo (uma grande área, entre as duas costas, pouco habitada e ocupada por novos bairros pobres).

Paralelamente a essas informações, foram pesquisadas fontes documentais e relatórios dos sindicatos patronal e trabalhista, boletins de informação das duas categorias e relatórios policiais de 114 pessoas.

Além da introdução e conclusões, o texto contém oito seções que tratam do transporte coletivo, trabalho e relações com o público, formas de violência e efeitos dos assaltos em termos de mortes, transtornos psíquicos, conflitos trabalhistas e medidas policiais.

\section{Panorama do transporte coletivo}

Para uma população de quase 2.400.000 habitantes e uma área de 710 quilômetros quadrados, Salvador possui uma frota de 2.500 ônibus

\begin{tabular}{lcc} 
Tabela 1 \\
\hline Assaltos a ônibus em cidades brasileiras, 1998. \\
\hline Cidades & Ocorrências & $\begin{array}{l}\text { \% } 1.000 \\
\text { habitantes }\end{array}$ \\
\hline São Paulo & 12.905 & 1,3 \\
Rio de Janeiro & 6.774 & 1,2 \\
Salvador & $3.407^{\star}$ & 1,5 \\
Recife & 2.754 & 2,0 \\
Vitória & 1.170 & 4,3 \\
Belo Horizonte & 712 & 0,3
\end{tabular}

Fonte: CNT (1999).

*Como essa cifra é apenas da delegacia

especializada, preferimos trabalhar com o número de 4.745 ocorrências, somatório dos valores dessa e de outras delegacias de Salvador (Tabela 2).

que, distribuídos em 462 linhas, transportam 36 milhões de passageiros por mês ou mais de um milhão por dia (SETEPS, 1998/99).

Aqui, como em outras capitais brasileiras, o uso do ônibus e de outros veículos automotores se generalizou sem as devidas precauções de engenharia, fiscalização e educação de trânsito, para controlar seus riscos. Além de numerosos acidentes diários, o transporte coletivo apresenta sérias deficiências - obsolescência parcial e má distribuição dos veículos, precariedade dos terminais, falta de abrigos para passageiros etc. -, que dificultam as atividades dos operadores e comprometem sua legitimidade junto ao público.

Nessas circunstâncias, o uso desse transporte reforça a separação material e simbólica entre famílias que possuem automóveis (23\%) e famílias que, não possuindo esse tipo de veículo (77\%) (Vasconcelos, 1999), são as mais prejudicadas pelas condições de operação dos veículos coletivos.

Se nos anos 90 não se vêem mais movimentos coletivos de depredação dos veículos de transporte (Moisés \& Martinez-Alier, 1978), nem por isso os aumentos de tarifas são recebidos passivamente. O peso delas no orçamento dos trabalhadores torna-os sensíveis às elevações de preço que venham aumentar seus custos e obrigá-los a substituir as viagens de ônibus por caminhadas a pé, como já fazem $29 \%$ da população urbana (Vasconcelos, 1999). Daí é que se originam muitos atos de resistência quotidiana (Scott, 1990) contra o pagamento das tarifas, nos quais passageiros entram em conflito com os operadores dos veículos.

As 18 empresas de ônibus (controladas por 13 proprietários) dispõem de 9.543 motoristas e cobradores, os quais, somados com 610 despa- 
chantes (ou controladores de tráfego), totalizam 10.153 rodoviários.

No topo desse sistema, a Secretaria Municipal de Transportes Urbanos (SMTU) controla as condições de operação dos ônibus em termos de linhas, frota, quadros de horários, tarefas e normas de conduta do pessoal de operação. Tal poder de regulamentação da STMU contrasta com sua timidez para melhorar o transporte (Siqueira et al., 1995) e a segurança dos veículos.

Empresários e trabalhadores estão representados por sindicatos atuantes. No caso do sindicato dos rodoviários, fundado nos anos 30 , a eleição de uma diretoria combativa em 1990 aumentou o poder de barganha, mas não equacionou os problemas de saúde e segurança ocupacional da categoria.

\section{Trabalho rodoviário}

Depois de ser nicho, durante muito tempo, de trabalhadores do sexo masculino, pouco escolarizados e não brancos, a ocupação de rodoviário vem se modificando com a admissão de mulheres, sobretudo como cobradoras, indivíduos mais escolarizados e pessoas brancas que não encontram trabalho no mercado metropolitano (Castro \& Sá-Barreto, 1998).

Uma característica marcante do trabalho dos rodoviários é eles não atuarem em um ambiente fixo, fechado e protegido como os locais de trabalho situados em edificações. Efetivamente, eles só comparecem às garagens das empresas em dois momentos da jornada diária: na hora da chamada "soltura", quando os ônibus são liberados para o trânsito, e no fim do turno para a prestação de contas. Outra especificidade está relacionada com o contato estreito do rodoviário com um público volátil que, possuindo como característica comum o uso do transporte, tem acesso indistinto ao interior dos veículos coletivos.

A jornada de trabalho de sete horas e vinte minutos, prolongada por horas extras, com pausas de 15 minutos entre as viagens, gera desgaste, tensão e insegurança generalizada. Nesse sentido, motoristas e cobradores vivenciam esses problemas de forma diferenciada. Gozando de maior prestígio do que os cobradores, os motoristas trabalham na direção dos veículos, enfrentando condições de tráfego desfavoráveis, fazendo movimentos repetitivos e atendendo demandas dos passageiros. Menos imobilizados nos seus assentos, os cobradores estão mais em contato com o público do que os motoristas. Entre os cobradores, estão incluídas mil mulheres que, embora valorizadas pela de- licadeza e honestidade, são tidas como mais vulneráveis às pressões dos usuários do que homens que ocupam a mesma função.

As pausas - essenciais - entre as viagens são julgadas insuficientes e comprometidas pelos atrasos nos percursos e falta de locais apropriados, fazendo com que os trabalhadores fiquem ao relento ou utilizem, contra o regulamento das empresas, as instalações de bares. Por maior que seja a precariedade, nesses locais é que se desenvolvem a sociabilidade, troca de informações e formação de grupos de apoio mútuo.

A gestão do trabalho envolve uma complexa rede que, além das empresas, inclui órgão público gestor e centrais de reclamação dos usuários. Um poderoso auxiliar para isso são aparelhos que, a exemplo de tacógrafos, drive-master e validadores, fazem o registro minucioso dos percursos dos rodoviários.

Ademais, dois tipos de fiscais - o fiscal secreto e o controlador de tráfego (ou despachante) - encarregam-se do gerenciamento do trabalho. Enquanto os fiscais secretos avaliam a conduta dos rodoviários nos percursos, os despachantes ficam localizados nos fins de linha, onde, através da autoridade e negociação, controlam o tempo de trabalho, trocas de turno, recolhimento dos carros e entrega do dinheiro para as empresas.

Pressionados por todos os lados, os rodoviários desenvolveram uma visão crítica do trabalho efetuado para empresas, as quais, só visando ao lucro, não demonstram preocupação com o bem-estar deles. Tal ponto de vista ganha mais concretude na fala de um motorista, Fortunato, 48 anos, negro, quando desabafa sobre seu dia-a-dia:

"A gente é um escravo, cem por cento ... qualquer mínimo de erro a gente tá levando ... é polícia que bate em motorista, agressão ... se você for tratar como é de direito você leva ... tem que ser maleável ... inclusive na empresa, independente de sexo, é punido, fica fora de escala, tudo é proibido, não tem direito, a gente trabalha sob pressão".

São essas condições de trabalho que geram estresse (França et al., 1998) e outras doenças citadas pelos trabalhadores. Na sua declaração de caráter sintético sobre os vários aspectos do processo saúde e doença, Roberto, 36 anos, pardo, cobrador, observou que, na ocupação, "a pessoa entra sã e sai doente do colesterol, sistema nervoso e falta de compreensão dos passageiros".

Gerando muitos atritos, as relações com os usuários constituem um dos pontos mais críticos da ocupação. 


\section{A confusão das normas}

As relações de cooperação e conflito no transporte coletivo se desenvolvem em um contexto no qual os rodoviários ocupam uma posição intermediária entre seus patrões e os passageiros. Se, por um lado, os primeiros são obrigados a obedecer a normas, por outro estão expostos às reações de desagrado dos últimos contra essas normas, sem dispor de instrumentos para se impor.

Conseqüentemente, os rodoviários adotam posturas negociadoras (maleáveis) para facilitar seu trabalho, que implicam relaxar no cumprimento das normas estabelecidas ou aceitar que essas sejam descumpridas pelos passageiros. Não é raro que, procedendo assim, os rodoviários se mostrem, especialmente no início da jornada de trabalho, receptivos com usuários igualmente cordiais.

Possuindo um caráter palpável para participantes e observadores, essas comunidades flutuantes, integradas por tripulantes e passageiros, não são suficientemente sólidas para controlar conflitos que, derivados das condições de operação, disposições dos rodoviários, atitudes dos usuários, normas de utilização e cobrança de tarifas dos veículos, contribuem para elas se tornarem incivilizadas (Elias, 1997; Sennett, 1993).

Se as condições de trânsito e operação dos veículos são um incentivo para a incivilidade, não se pode desprezar a postura dos trabalhadores de transferir sua insatisfação ("descontar") para o público. Expressando resistência contra as condições de trabalho, os atos de imprudência no trânsito, causadores de muitos acidentes, e insultos aos passageiros são uma válvula de escape que, antipatizando a categoria junto ao público, alimenta hostilidade contra ela.

Quanto aos usuários, a insatisfação deles com descompassos entre oferta e demanda de veículos, com esperas prolongadas em paradas sem abrigo e policiamento, com superlotação dos veículos, com engarrafamentos no trânsito e com calor interno excessivo, leva-os a adotar condutas agressivas uns com os outros e com os rodoviários.

Essas reações acendem conflitos como os que se vêem nos itinerários dos bairros populares do Miolo e da Baía, onde o transporte coletivo é precário, ou nos fins de semana, dias de festas ou jogos de futebol. Nessas situações, usuários animados fazem música e brincadeiras, mas também provocam brigas e cometem atos de vandalismo, quebrando vidros e assentos, escrevendo grafites etc. No caso de uma empresa entrevistada, os prejuízos com o vandalismo superavam o valor roubado nos assaltos.

Nessa arena de interações com estranhos, displicentes ou hostis, a vulnerabilidade do trabalhador torna virtualmente impossível a manutenção dos regulamentos. Um exemplo disso é a resistência de passageiros (traseiristas) a passar pela roleta e pagar a passagem, bloqueando a entrada de outros passageiros. Isso é o que foi dito por Paulo, 29 anos, pardo, cobrador: "eles [os passageiros] não conhecem as regras, pensam que é a gente que cria ou faz elas, não sabem que a gente segue ordens da empresa, a culpa de tudo é nossa".

De acordo com a postura subserviente esperada dos subalternos, inclusive da parte de outros subalternos, há um entendimento que os operadores não devem reclamar do comportamento dos passageiros, para não caírem no desagrado, sofrerem ameaças ou serem fisicamente agredidos por estes.

Esses conflitos se exacerbam nas situações em que os passageiros buscam sonegar o pagamento da passagem ("calote"), passando pela roleta e desafiando o cobrador. Essa cena é o inverso de outra, na qual os rodoviários permitem aos amigos fazerem viagens gratuitas (“carona"), contribuindo para legitimar a sonegação por parte de outros passageiros. Essa situação de conflito, em que o passageiro recusa pagar a passagem, pode envolver o confronto de grupos de usuários, armados ou não, com o cobrador. Causando prejuízos financeiros e agressões físicas, como espancamentos e apedrejamentos dos que tentam resistir, essa forma de sonegação é tida como uma violência insuportável por acontecer sob as vistas de espectadores.

Semelhante ao calote, no que se refere ao prejuízo financeiro causado ao rodoviário, a extorsão ("pedágio") paga a indivíduos suspeitos, os chamados marginais, é menos humilhante. Diante da possibilidade sempre presente de extorsão, o cobrador já separa o dinheiro de uma tarifa (ou duas) para pagá-la. Embora também o limite da recusa seja a violência, às vezes precedida por rixas, nas quais o rodoviário é lembrado ("marcado") para apanhar, o pedágio não é percebido como um ato violento, e, acontecendo através de um acordo tácito, exclui, em princípio, a humilhação pública que acontece no calote.

Sem deixar de atingir cobradores distraídos, as ações de ladrões denominados lanceiros (pickpockets) visam principalmente aos passageiros. Essas ações podem acontecer de modo furtivo, sem o conhecimento dos usuários, ou então envolver ameaças, claras ou insi- 
nuadas, de violência contra as vítimas ou possíveis testemunhas.

Conquanto caloteiros, cobradores de pedágio e lanceiros, que foram os primeiros a mostrar o caminho para ganhar dinheiro ilicitamente no transporte coletivo, continuem a fazer parte do cenário dos ônibus, eles vêm cedendo lugar a delinqüentes que empregam (ou simulam empregar) armas de fogo para subtrair a arrecadação dos veículos e pertences dos passageiros.

O exame de relatórios policiais acerca de 88 assaltantes mostrou que estes eram, salvo uma única mulher, do sexo masculino. A média de idade era 21 anos; $80 \%$ dos indivíduos tinham até 24 anos e $11 \%$ eram menores de idade que roubavam sozinhos ou ajudavam, dentro de um arranjo recorrente, assaltantes mais velhos. Quanto à origem étnica, havia dois terços $(71,6 \%)$ de pardos, para um terço $(28,4 \%)$ de negros (Paes-Machado \& Levenstein, 2000).

A quantia média, por assalto, é de aproximadamente setenta reais e os infratores agem nos trechos das linhas que apresentam pontos de fuga. Esses trechos estão localizados, na sua quase totalidade, nos bolsões de pobreza, favelas e invasões das já mencionadas áreas da Baía e do Miolo de Salvador, onde também estão situados os endereços dos assaltantes (SSP/Polícia Militar do Estado da Bahia, 1999).

O turno preferido é o da noite, com $45,1 \%$ das ocorrências na faixa das $18 \mathrm{~h}$ às $22 \mathrm{~h}$, seguido pelo vespertino $(27,8 \%)$ e matutino $(14,3 \%)$ (SETEPS, 1998/1999). Tal variação está relacionada com o volume de dinheiro e facilidades de fuga dos ônibus. Atentos aos horários de maior arrecadação, mas evitando, acima de tudo, ônibus lotados, os assaltantes agem principalmente nas paradas próximas aos fins de linha e trechos em que os veículos estão vazios. Além da dificuldade de controle, a presença de muitas pessoas juntas estimula disposições de defesa que podem ocasionar a morte ou prisão deles.

Os dias mais visados são domingo (18,5\%), sábado $(16,2 \%)$ e sexta-feira $(14,3 \%)$, que somam metade das ocorrências. Além da menor lotação e policiamento urbano, o que conta aqui é a necessidade ("abafamento") de dinheiro para o fim de semana. Por essa razão, a sexta-feira é chamada de dia de Nossa Senhora da Providência, quando quem não conseguiu dinheiro durante a semana tem toda a chance de obtê-lo.

Quanto ao calendário anual, os meses de abril $(11,7 \%)$, junho (10,6\%), julho $(9,3 \%)$, maio $(9,3 \%)$ e março $(9,0 \%)$ apresentavam o maior número de assaltos (SETEPS, 1998/1999). Sem que se tenha uma explicação definitiva para isso, vale referir que esses meses possuem, pre- cedem ou sucedem momentos festivos, como Carnaval, Semana Santa ou São João, com apelos de consumo e necessidades de gastos.

\section{As cifras do assalto}

As cifras relativas aos assaltos de veículos coletivos verificados nos últimos dez anos, 20.751 ocorrências, mostram que estas cresceram $888 \%$ entre $1990 / 1998$, o que significa dizer que cada rodoviário (motorista e cobrador) foi assaltado mais de duas vezes no período.

Um olhar mais atento para esses valores, no entanto, revela que eles apresentam sérios problemas, como a omissão de eventos, que, caso registrados, dariam uma visão mais realista da situação (Tabela 2).

Começando pelo ano base de 1990, o registro policial ignora as centenas de ocorrências que já se verificavam, antes dessa data, no transporte coletivo. Por sua vez, quando esquadrinhamos a rubrica policial "assaltos de ônibus”, verificamos que esta compreende apenas os eventos acontecidos no interior dos veículos, sendo incluídas em outras rubricas inúmeras ações criminosas contra trabalhadores do transporte nos momentos em que eles descem dos veículos.

Com respeito aos dados sobre valores roubados e fatalidades ocorridas, a incompletude também salta aos olhos. Refletindo a orientação dominante do sistema penal, de se preocupar apenas com o patrimônio das empresas, as cifras dos prejuízos não computam valores pessoais roubados aos trabalhadores e passageiros. Se fossem registradas, essas perdas fariam triplicar ou quadruplicar o volume dos prejuízos, dando visibilidade a esses perdedores e, no limite, facilitando ações judiciais de ressarcimento de prejuízos contra as empresas de ônibus.

Quanto às fatalidades causadas pelos assaltos, as omissões se referem tanto à polícia, que só passou a distinguir homicídios nos ônibus em 1995-1996, como às empresas e ao próprio sindicato dos rodoviários. O sindicato, apesar da sua luta contra a insegurança no transporte coletivo, apresenta apenas números parciais e genéricos para o período 1990-1996, quando a polícia, diga-se de passagem, ainda não possuía registros específicos desse tipo de delito. Sintomaticamente, quando a polícia começou a fazer o registro das fatalidades, o sindicato dos rodoviários deixou de ter seu próprio registro.

Em meio a essas lacunas, os números disponíveis do sindicato dos rodoviários e da polícia assinalam a morte de 67 pessoas nessas ocor- 
Número de ocorrências, valores roubados e fatalidades nos assaltos a ônibus. Salvador, Bahia, Brasil, $1990 / 1999$.

\begin{tabular}{|c|c|c|c|c|c|c|c|c|}
\hline \multirow[t]{2}{*}{ Anos } & \multirow[t]{2}{*}{ Ocorrências } & \multirow[t]{2}{*}{ Valores (R\$) } & \multirow[t]{2}{*}{ Média (R\$) } & \multicolumn{5}{|c|}{ Fatalidades por fontes } \\
\hline & & & & $A^{2}$ & $\mathrm{~B}^{3}$ & B4 & B5 & $A+B+B+B$ \\
\hline 1990 & 539 & * & * & * & * & * & * & * \\
\hline 1991 & 964 & * & * & * & * & * & * & * \\
\hline 1992 & 1.285 & $\star$ & * & * & * & * & * & * \\
\hline 1993 & 1.476 & * & * & * & * & * & * & * \\
\hline 1994 & 1.530 & * & * & * & * & * & * & * \\
\hline 1995 & 934 & * & * & * & * & 1 & * & 1 \\
\hline 1996 & 2.210 & $155.274,011$ & 70,3 & * & 7 & * & * & 7 \\
\hline 1997 & 4.219 & $345.623,47$ & 81,9 & * & 2 & * & * & 2 \\
\hline 1998 & 4.745 & $333.563,78$ & 70,3 & * & 7 & 4 & * & 11 \\
\hline 1999 & 2.849 & $224.023,24$ & 83,9 & * & 2 & * & 20 & 20 \\
\hline Total & 20.751 & $1.058 .484,50$ & 51,5 & 24 & 18 & 5 & 20 & 67 \\
\hline
\end{tabular}

Fonte: Polícia Civil, Polícia Militar e Sindicatos das Empresas e dos Rodoviários.

*sem informação

1 Só inclui os valores computados entre maio e dezembro de 1996.

2 Dados do Sindicato dos Rodoviários, que incluem apenas os rodoviários mortos entre 1990 e 1996, sem especificação de ano.

3 Dados da Polícia Militar, que agregam rodoviários e passageiros mortos.

4 Dados da Polícia Militar, que incluem somente os policiais mortos.

5 Dados da Polícia Militar sobre assaltantes mortos.

rências. Entre as vítimas, o sindicato contabilizou 24 rodoviários, de 1990 a 1996, enquanto a polícia registrou, de 1995 a 1999, 43 pessoas mortas, distribuídas entre: trabalhadores e passageiros (18), policiais (5) e assaltantes (20) (Tabela 2).

Se, hipoteticamente, adicionarmos oito fatalidades para o período de 1996-1999 aos 24 rodoviários mortos entre 1990 e 1996, teremos um total de 32 óbitos de trabalhadores em uma década, o que faz com que os rodoviários sejam o segundo grupo mais vitimado depois dos assaltantes. Enquanto o número de trabalhadores mortos está distribuído ao longo do período, as vinte mortes de assaltantes correspondem a um período de apenas dez meses (janeiro a outubro de 1999). As implicações desse fato serão discutidas adiante, quando tratarmos dos métodos policiais de combate aos assaltos.

\section{Roteiros perigosos}

Parecidos aos roteiros (scripts) comuns, pelas seqüências compreensíveis de eventos, os roubos de coletivos diferem deles por terem seqüências imprevistas e virtualmente desastrosas para os participantes (Linger, 1992). Esses roteiros são: assaltos nos fins de linha e assaltos aos ônibus em movimento, subdivididos em ações contra o cobrador e ações extensivas aos demais ocupantes dos veículos.

Os assaltos nos fins de linha, não computados nas cifras gerais das ocorrências, são feitos por grupos de rapazes (quadrilhas) que, controlando territórios nos bairros populares (PaesMachado \& Tapparelli, 1996), estendem esse domínio aos ônibus que por ali circulam. Aproveitando-se das pausas, já descritas antes, eles assaltam vários ônibus ao mesmo tempo, roubam rodoviários, cobram tarifas dos passageiros etc. Tendo acabado em nove das 11 linhas aqui estudadas, por conta do aumento do policiamento, esses fatos persistem em dois terminais do Miolo de Salvador, onde ocorrências violentas levaram rodoviários a pedir transferência para outras linhas de ônibus.

Nas ações visando ao cobrador, nos veículos em movimento, um (ou mais de um) assaltante rende e toma os valores do primeiro. Nesse evento, sobretudo quando é protagonizado apenas por um ladrão, este rouba o trabalhador sem ser visto pelos demais. Em outros casos, o roubo do cobrador envolve dois assaltantes um na parte dianteira e outro na parte traseira - e é presenciado por todos.

Para potencializar os recursos e contrabalançar o "rendimento decrescente" da cooperação, infratores em grupo, que se revezam para não serem reconhecidos, cometem ações mais ousadas. De acordo com isso, dois, três ou qua- 
tro ladrões se apossam do veículo, rendem, roubam o cobrador e fazem o saque dos passageiros. $\mathrm{O}$ aspecto perverso desses saques é que eles prejudicam mais os trabalhadores pobres que, não possuindo cheques e cartões de crédito, costumam carregar consigo todo dinheiro que recebem ou necessitam para suas despesas.

Embora essa conduta predatória faça pensar que os infratores são seres impiedosos, alguns relatos revelam que eles podem ter compaixão pelo outro, especialmente se este é conhecido, como ficou patente na reação de um infrator que, ao identificar sua professora no meio dos passageiros, alertou o colega: "Essa aí não assalta, é minha professora" (professora de colégio, 62 anos).

Os assaltantes por mais tensos que estejam dão demonstrações de irreverência, como se verificou em um evento em que um deles, depois de haver saqueado todo mundo, falou: "Desculpem gente, mas isso é o Brasil" (Norberto, 36 anos, pardo, cobrador).

Contribuindo para impedir o pior, certas iniciativas de rodoviários e passageiros ajudam a controlar o nervosismo reinante e evitar resistências arriscadas. Uma ilustração dessa mediação está no relato de Jandira sobre um assalto praticado por três rapazes:

"Eles roubaram todos os passageiros e falavam: 'Motorista, qualquer coisa você é o primeiro que morre'. (...) Diziam para mim e para a passageira que também estava com um deles na frente 'vagabunda, desgraça, tá vendo que é um assalto'. Essa passageira ainda me disse depois que só entregou o dinheiro por minha causa, que eu tinha ficado nervosa. (...) Eu falei: 'Perder a vida por causa de cem, oitenta reais?'. Ao mesmo tempo que eu fiquei nervosa, eu também pedia calma às pessoas, tive força na hora, falava com ela: 'Moça, pelo amor de Deus entregue logo o dinheiro' [e] falava com o assaltante: 'Você não precisa atirar em ninguém, todo mundo vai entregar tudo rapaz'. (...) As pessoas ficavam nervosas, tinha uns gringos que não entendiam nada, começaram a chorar."

Em alguns casos, esse roteiro se desdobra em seqüestros, nos quais o motorista é forçado a mudar o itinerário e levar o veículo para locais isolados. Como esse tipo de ação, acompanhado por mudanças dos trajetos, pode despertar a atenção de policiais e transeuntes, ele se verifica nas linhas que servem a áreas menos povoadas, onde são encontrados terrenos baldios para ocultar os veículos.

A imprensa e os inquéritos, no entanto, chamam atenção para seqüestros feitos por ladrões de estabelecimentos comerciais em fuga. Num evento dessa ordem, um assaltante de uma ca- sa de loteria fugiu em um ônibus que estava sendo assaltado por outros infratores e ao ver o veículo cercado pela polícia, gritou para esta: "Eu não sou assaltante de ônibus, sou assaltante de banco" (SSP/Polícia Civil do Estado da Bahia, 1999).

As circunstâncias que favorecem mortes violentas e homicídios ocupacionais no interior dos veículos coletivos são examinadas no que se segue.

\section{A féria ou a vida}

Reproduzindo padrões de conduta universais, os infratores trabalham para criar a ilusão da morte (ou dano) iminente da vítima, por meio de uma atuação agressiva que visa a obter o consentimento daquela (Wright \& Decker, 1997). Contudo, entre a intenção e o resultado, há dificuldades que, comprometendo a qualidade da representação, precipitam finais desastrosos para todos: tipo de arma, reações confusas dos participantes, uso da força por particulares e agentes de segurança.

Vistas como um fator determinante da letalidade das agressões ocupacionais (NIOSH/ CIB, 1996), as armas de fogo nem sempre estão presentes nos assaltos de ônibus. Ao lado de indivíduos que empregam essas armas para submeter as vítimas - mediante uma ordem de rendição (voz de assalto), que é o orgulho do bandido (Paes-Machado \& Tapparelli, 1996) -, um quarto dos infratores não porta armas de fogo (SSP/Polícia Civil do Estado da Bahia, 1999).

Na ausência desse tipo de arma, uma parte dos infratores emprega - por amadorismo, falta de dinheiro ou por não querer maiores complicações legais - armas brancas, faz menção de trazer armas escondidas ou carrega revólveres de brinquedo. Poupando as vítimas, mas abusando da representação, ladrões desarmados arriscam ser apreendidos, espancados ou mortos por ocupantes irados, inclusive por terem sido enganados, ou pela própria polícia.

Para reduzir, mas sem eliminar de todo, o risco de serem dominados pelos ocupantes dos veículos, infratores precavidos não abrem mão de armas de fogo. $O$ uso da força, em certos casos pode ir além da pura rendição, como em cenas em que os assaltantes, visando à imobilização completa das vítimas, ordenam que estas tirem as roupas.

Essa dramaturgia, todavia, tem a desvantagem de aumentar o medo pânico das pessoas, produzindo reações confusas, julgadas perigosas pelos assaltantes, e favorecendo agressões letais contra tripulantes e ocupantes dos veí- 
culos, como relatou Lúcia, 39 anos, parda, cobradora, ao falar sobre dois colegas mortos "por besteira":

"Um deles [estava com] o dinheiro no bolso de trás da calça. Quando o assaltante pediu o dinheiro, ele foi pegar, aí o assaltante achou que ia pegar uma arma e atirou nele. O outro colega de trabalho já tinha sido assaltado e ainda estava pagando o prejuízo para a empresa. Então quando o assaltante chegou para pedir o dinheiro, ele falou 'você de novo!' O assaltante foi, pegou o dinheiro, desceu pela porta de trás e deu um tiro nele, na certa com medo de que ele o identificasse."

Essa dificuldade de continuar a representação, nem que seja através do improviso, é de todos. Quanto mais os assaltantes são capazes de controlar o medo e o pânico, mais eles sabem distinguir, no comportamento das vítimas, reações confusas de verdadeiras ameaças.

Isso não é o que acontece com amadores que, sob forte tensão ou efeito de substâncias psicoativas, têm mais facilidade para disparar o gatilho do que indivíduos experientes. Esse parece ter sido o caso de dois adolescentes de 16 e 17 anos que, estando fora de si ou nervosos, assassinaram duas rodoviárias, uma por estar sem dinheiro e outra por tentar reagir, segundo Gildo, 32 anos, pardo, despachante.

Enquanto muita gente logra superar o choque da agressão, aceitar perdas e cooperar com os infratores, um menor número de indivíduos não reage do mesmo modo ou parte para o contra-ataque. Aproveitando-se da fraqueza ou desatenção dos assaltantes, rodoviários e passageiros se atracam com aqueles para tentar dominá-los. Ao lado de tentativas bem-sucedidas, há fracassos que culminam na morte dos contra-atacantes.

Um agravante desse quadro de violência decorre da presença de passageiros armados, policiais ou não, fazendo dos veículos um campo de batalha de uma guerra que não cessa de provocar baixas (STTR-BA, 1996). Tal uso de armas deve ser visto em um contexto maior de disseminação das mesmas, seja como alternativa de autodefesa (Noronha \& Paes-Machado, 1999), seja como instrumento de trabalho (o caso dos policiais e vigilantes). Vale acrescentar que, nessa escalada de violência, vários policiais foram mortos simplesmente pelo fato de terem sido reconhecidos pelos delinqüentes. Esses casos, por sua vez, reforçam motivações revanchistas da polícia no sentido de eliminar fisicamente os assaltantes, como abordaremos adiante.

Por estarem expostos a esses eventos extremos, os operadores desenvolveram distúrbios psicológicos caracterizados pela dificuldade de superação da cena traumática.

\section{Sob o domínio do medo}

Os sucessivos traumas experimentados pelos que trabalham nos veículos coletivos provocam ansiedade, transtornos de medo e conflitos de identidade. O núcleo principal está referido ao medo do desaparecimento físico, tal como foi expresso por Amarildo: "[A pessoa] sente nervosismo, a pessoa pensa que não vai ver ninguém, eu pensava que nunca mais ia ver minha família, é um negócio estranho."

A associação entre existência (e segurança) individual e pertencimento ao grupo doméstico não chega a ser abalada pelas narrativas de agressões que ocorrem em toda a cidade e, conseqüentemente, nos espaços residenciais dos trabalhadores. Assim, por mais que os riscos de assaltos no local de residência, ou entre este e o local de trabalho, comprometam a imagem da segurança familiar e relativizem o peso das agressões no ambiente de trabalho, este continua sendo visto como o mais inseguro. De resto, essa visão é partilhada pelas esposas, que, temendo e vivendo sob tensão por seus maridos (e provedores), reforçam a apreensão dos mesmos quanto aos perigos do trabalho realizado no transporte da população metropolitana.

Outro conjunto de narrativas faz menção aos choques emocionais produzidos pelas agressões no ambiente de trabalho, tal como é citado por Júlio, 31 anos, pardo, motorista: “No momento a gente apenas não reage, apenas fazo que ele pede. Após o assalto é que o choque vem, no momento você fica neutro, depois é que vem o nervosismo."

Comentando a dificuldade de superação do evento traumático, uma cobradora entrevistada afirmou: "Levei um susto ... nossa, senti um medo danado, fiquei tremendo que nem vara verde (...) no nosso trabalho a gente supera tudo, mas assalto a gente não supera" (Clarice, 42 anos, parda).

Numa linha próxima dos chamados distúrbios pós-traumáticos (Kleinman, 1995), o relato de um motorista salienta, como conseqüências dos eventos, a somatização dos sintomas em termos de sensibilidade aguda a ruídos e ansiedade: "Você ficar com revólver no ouvido, o cara ali xingando a gente, isso deixa qualquer um neurótico. É um trauma para o resto da vida, hoje eu nem posso ouvir alguém falar mais alto (...) eu era muito calmo, hoje não consigo mais ser" (Joseval, 58 anos, branco).

Além de sentir mais tensão e trabalhar assustado (França, 1995), o rodoviário desenvolve um tipo de transtorno que o leva a ver assaltantes, especialmente no turno da noite e em linhas mais perigosas, nas figuras de passagei- 
ros comuns. Esse transtorno pode ser visto na declaração de um despachante que trabalhou como motorista: "Dá medo, trauma, a gente fica desconfiado quando entra no ônibus, achando que todo mundo vai ser assaltante, (...) porque o assalto não tem hora certa, a gente não sabe" (Abdias, 40 anos, negro, despachante).

O transtorno de medo é confirmado por outro depoimento acerca da percepção modificada dos rodoviários com respeito ao seu trabalho, na qual o próprio fluxo de passageiros é tomado como uma ameaça: "Devido ao assalto, você fica achando que vai ser assaltante, é o pânico; sinceramente, cada passageiro que entra você pensa que aquele pode ser o assaltante" (Mariza, 29 anos, parda, cobradora).

Numa outra linha, pode-se afirmar que a violência dos assaltos abala a identificação do rodoviário com seu trabalho, intensificando a sensação de perda de controle sobre sua função e ambivalência de status dentro da hierarquia da empresa. A sensação de perda de controle pode ser vista na situação típica em que o assaltante, ao render tripulação e ocupantes do veículo, chama para si toda a responsabilidade antes depositada no motorista e no cobrador. Se, do ponto de vista do motorista, esse evento é rebaixador - fazendo-o perder a posição de condutor para passar à de conduzido -, da perspectiva do cobrador ele representa uma desmoralização. Isso porque os cobradores, situados na posição liminar e desconfortável de zeladores do dinheiro de terceiros, passam a ser vistos segundo estereótipos negativos ou ambíguos, que colocam em questão sua responsabilidade profissional e honra pessoal: vítimas e culpados, corajosos (machos) e covardes, representante dos interesses da empresa e oportunistas contumazes.

Não seria exagerado dizer que esse mal-estar, psicológico e social, está na origem dos veementes protestos sindicais da categoria nas vias de circulação e espaços públicos da cidade, na segunda metade dos anos 90 .

\section{Protestos sindicais}

Os conflitos entre patrões e empregados decorrem da posição dos primeiros quanto ao pagamento de roubos. Conquanto o prejuízo médio mensal, de menos de mil e quinhentos reais por empresa em 1998, seja irrisório e não as motive fazer um seguro específico contra assaltos, nem por isso elas estão dispostas a arcar com as perdas.

Tal postura decorre do poder do patronato para definir a situação e impor as regras mais convenientes para ele. Assim, dentro da ótica do trabalhador agradecido aos seus empregadores (Pegoraro, 1999), os rodoviários devem assumir os riscos dos assaltos e, inclusive, pagar um montante que, segundo dirigentes sindicais, chega a atingir $55 \%$ do total dos prejuízos financeiros causados pelas ocorrências.

Confrontadas com perdas na arrecadação que podem vir a comprometer sua rentabilidade, as empresas intensificam a pressão sobre os cobradores. Nesse sentido, elas vêm forçando os cobradores a tomarem mais cuidado com o dinheiro, sem oferecer respostas para os problemas de segurança colocados pela circulação da frota de veículos na área metropolitana. Os cuidados se referem basicamente ao controle do numerário, fazendo com que o cobrador não junte muito dinheiro na sua mão. De acordo com isso, os cobradores, do segundo e terceiro turno, devem depositar uma parte da arrecadação em cofres, que só são abertos nas garagens das empresas, ou improvisar lugares que podem ser a parte dianteira do ônibus ou as roupas íntimas. Esses expedientes podem, em certos casos, levar os assaltantes a desenvolver um tipo particular de violência contra o corpo dos rodoviários, fazendo com que tirem as roupas e machucando partes corporais sensíveis como, por exemplo, os seios das cobradoras.

Ora, se esses expedientes funcionam em assaltos breves, em que os ladrões levam o que podem, o mesmo não se aplica às ocorrências em que os assaltantes dispõem de tempo para maximizar seus ganhos. Diante do dilema da féria ou a vida, o preço da integridade física para o trabalhador é a sanção de ressarcir o valor roubado que ultrapasse a importância de $\mathrm{R} \$ 80,00$ ou cem tarifas de ônibus, por meio de descontos, chamados de "empréstimos", dos contracheques.

Quanto aos cobradores dos ônibus do primeiro turno, que só são recolhidos no final do turno seguinte, eles não depositam o dinheiro arrecadado no cofre, para evitar que este se misture com a arrecadação do segundo turno, mas são obrigados igualmente a pagar se não tiverem testemunhas, fato comum, como foi visto, nos assaltos individuais.

A outra fonte de insatisfação deriva do que os empregados consideram falta de apoio da empresa e morosidade da previdência social para pagar a licença do trabalhador gravemente vitimado. Isso é o que disse José, 34 anos, pardo, despachante:

"A ajuda que a família [do trabalhador] acha é dos rodoviários; (...) a gente faz uma lista para arrecadar dinheiro. (...) Isso acontece quando o cara tá doente ou então tem casos que 
o cara levou uma coronhada e é afastado do trabalho por um período longo, depois de quinze dias, que é tempo de atestado da empresa. A gente ajuda até o benefício do INSS sair, porque demora, senão a empresa deixa é passar fome."

Alimentada pelo crescente medo dos assaltos, essa insatisfação motivou mobilizações que, começando em 1992, atingiram seu clímax nos protestos verificados, entre 1995 e 1996, contra a morte de vários rodoviários. Envolvendo a realização de trinta paralisações, acompanhadas por apelos aos ladrões para não matarem rodoviários, essa campanha deu visibilidade pública a um problema considerado, até esse momento, como exclusivo dos trabalhadores e usuários mais pobres do transporte coletivo.

Um efeito dessas campanhas foi a retirada dos painéis de propaganda dos pára-brisas traseiros, que comprometiam a visibilidade do interior dos veículos, e a adoção desigual, e não muito eficaz, de outras medidas de segurança interna dos ônibus - alarmes luminosos, cofres reforçados etc. O outro efeito foi a criação de uma operação policial de combate aos roubos de coletivos.

\section{A segurança policial}

O medo social, os protestos sindicais e o clamor público suscitados pela onda de assaltos de ônibus obrigaram as polícias militar e civil a renovar técnicas de policiamento, em virtude da desarticulação entre as duas forças, falta e má distribuição dos efetivos e ineficiência.

A primeira força mobilizada foi a Polícia Militar, em 1997, por meio da criação de um efetivo de 250 policiais encarregados da vigilância dos ônibus de passageiros. A grande novidade tática adotada foi o policiamento das paradas, combinado com rondas móveis nos trajetos dos ônibus. Essa operação acabou, no final de dois anos, com os assaltos em muitos fins de linha, mas não impediu que eles se multiplicassem nos trajetos dos ônibus (Mário, 42 anos, oficial da polícia, pardo).

Além da guerra de movimento dos assaltantes, essa modalidade de policiamento foi prejudicada pela falta de empenho da polícia civil para investigar, deter e indiciar os infratores, fazendo com que, para 1.869 ocorrências de assaltos, entre janeiro e julho de 1999, fossem efetuados apenas 26 inquéritos. Constatada a ineficiência policial para reduzir o número de ocorrências, as autoridades públicas organizaram uma unidade especial de combate aos delitos: a delegacia de repressão aos assaltos de veículos coletivos.
Marcando um maior endurecimento da postura contra a criminalidade, a criação dessa unidade apresenta dois importantes aspectos. Primeiro, o avanço da privatização da segurança pública (Caldeira, 1997), mediante a transferência de recursos financeiros e materiais das empresas de ônibus para as polícias. Segundo, e dados os limites da polícia para conciliar eficiência e respeito aos direitos humanos (Soares, 2000), a adoção da nova modalidade de policiamento significou uma intensificação do uso da força letal contra infratores (Adorno \& Cardia, 1999).

Esse uso da força letal transparece na morte de vinte infratores apenas no ano de 1999, para cinco policiais mortos entre 1995 e 1999. Outra expressão disso é a generalização do verbo "tombar", aplicado a coisas que caem, nas páginas dos jornais e falas de agentes policiais para nomear esses homicídios (police homicide). Trata-se de óbitos que funcionam como mortes anunciadas para aqueles que, insistindo nos assaltos, desacatam a autoridade ou tornam derrisório o esforço das autoridades para controlar a situação. A essas ações devem ser creditadas o decréscimo de quase um terço das ocorrências em 1999, com respeito aos anos de 1998 e 1997 (Tabela 2).

Não havendo elementos, entretanto, para afirmar que os assaltos vão continuar caindo, o mais provável é que eles se estabilizem em um patamar menor, mas ainda assim significativo para a frota de ônibus. Podendo ser vistos como uma encenação do drama do desemprego juvenil, os assaltos de veículos coletivos como modalidade de ganho rápido vão persistir, porém com menos intensidade do que antes, quando um só infrator chegava a cometer três ou quatro assaltos por dia.

Em adição, os bandidos devem redimensionar suas ações, adotando estratégias mais diversificadas, calculadas e, provavelmente, mais arriscadas.

\section{Conclusões}

No exame das manifestações de violência ocupacional no transporte coletivo de uma metrópole brasileira, debruçamo-nos sobre conflitos, individuais e coletivos, ligados ao cumprimento das normas e à apropriação ilícita de recursos materiais. Além de muitos usuários não quererem respeitar as normas de uso e pagamento das tarifas do transporte, jovens assaltantes roubam uma parcela da arrecadação das empresas e pertences dos usuários, através de atos de violência contra estes e os rodoviários. 
Às vantagens do transporte coletivo como alvo fácil, assinaladas pela literatura internacional - a presença de trabalhadores que manipulam dinheiro, fazem deslocamentos, atuam sozinhos (ou em duplas), em turnos da noite e em áreas dominadas pelo crime -, é necessário acrescentar mais dois aspectos importantes. Primeiro, os ônibus, tais como outros meios de transporte urbano, podem ser roubados e, ao mesmo tempo, empregados como meio de fuga. Segundo, o espaço dos ônibus é perigoso, de difícil policiamento, uma vez que a ação da polícia pode colocar em risco a vida de todos que estão no seu interior.

Além de indicar situações facilitadoras de homicídios - uso de armas de fogo, reações nervosas dos participantes, emprego da força por particulares e agentes de segurança -, o estudo constatou a dificuldade dos participantes para controlar os desfechos desses encontros perigosos, caracterizados por interações imprevisíveis, dinâmicas e virtualmente desastrosas para eles. Essa dificuldade é um sério desafio para o desenvolvimento, mediante ações educativas, de habilidades (skills) de autocontrole, negociação de conflitos e neutralização de agressões.

Apresentado como o principal mecanismo de controle da criminalidade ocupacional, o uso da força policial criou sérios problemas para os trabalhadores e o público, dentro e fora dos veículos coletivos. As abordagens e revistas policiais nas paradas de ônibus constituem um transtorno para os usuários, seja pela perda de tempo, causada pela obrigação de descer nos pontos de abordagem, seja pelo desrespeito aos seus direitos de cidadãos. Outrossim, a ação policial, por meio do confronto direto e eliminação física dos infratores, aumentou o medo e o pânico, assim como os riscos de fatalidades no interior dos veículos.

Apesar do seu sucesso na redução das ocorrências, fica clara a necessidade de medidas adicionais para enfrentar os problemas de segurança e saúde colocados pela violência no transporte coletivo. Uma das mais importantes é o acompanhamento psicológico, proporcionando meios aos rodoviários para recuperar a auto-estima, controlar o estresse, negociar conflitos com os usuários (os quais também devem ser alvo de campanhas educativas sobre seus direitos e deveres) e assaltantes. Somente dessa forma serão criadas condições para os rodoviários superarem e/ou minimizarem patologias psicológicas que se traduzem em estados de medo, conflitos de identidade e sentimentos persecutórios.

Paralelamente a isso, torna-se urgente o debate público qualificado sobre os elevados níveis de violência e insegurança no trabalho hoje existentes na área metropolitana. Acima de tudo, devem ser combatidas as condições de exclusão econômica, social e cultural que favorecem o ingresso de jovens pobres em atividades predatórias contra trabalhadores e usuários dos transportes coletivos e, em geral, dos serviços urbanos.

\section{Agradecimentos}

Agradecemos o apoio recebido do Programa A Cor da Bahia/Fundação Ford e da assistente Mônica Ribeiro Moreira, que participou do trabalho de campo. Esses agradecimentos são extensivos aos que gentilmente comentaram versões anteriores desse texto: os membros do Grupo de Trabajo Violencia y Sociedad, Consejo Latinoamericano de Ciencias Sociales; Sylvia Tesh, Yale University; Naomar de Almeida Filho, Maurício Barreto, Ceci Vilar Noronha e Vilma Santana, do Instituto de Saúde Coletiva, e Carlos Linhares, da Universidade Salvador. 


\section{Referências}

ADORNO, S. \& CARDIA, N.,1999. Dilemas do controle democrático da violência: Execuções sumárias e grupos de extermínio. In: Violência em Tempo de Globalização (J. V. Tavares-dos-Santos, org.), pp. 66-90, São Paulo: Editora Hucitec.

BELKIE, K. \& SCHALL, P., 1998. On a San Francisco public transportation line: Burden and consequences upon the human operator. In: San Francisco Bus Drivers Study (K. Belkie \& P. Schall, ed.), pp. 20-45, San Francisco: San Francisco Municipal Railway/Transport Workers Union/The City of San Francisco.

CALDEIRA, C., 1997. Segurança pública e seqüestros no Rio de Janeiro (1995-1996). Tempo Social, 9:115155.

CASTRO, N. \& SÁ-BARRETO, V. (org.), 1998. Trabalho $e$ Desigualdades Sociais. São Paulo: Annablume/A Cor da Bahia.

CNT (Confederação Nacional de Transportes), 1999. Revista Transporte. Brasília: Mídia Brasil Consultoria e Comunicação.

ELIAS, N., 1997. Os Alemães. Rio de Janeiro: Jorge Zahar.

FRANÇA, A.; SANTOS, C. \& RUBINO, P., 1998. Violência no Trabalho e Sofrimento Mental. Salvador: Universidade Federal da Bahia.

KLEINMAN, A., 1992. Writing at the Margin. Berkeley: University California Press.

LINGER, D., 1992. Dangerous Encounters. Stanford: Stanford University Press.

MOISÉS, J. A. \& MARTINEZ-ALIER, V., 1978. A revolta dos suburbanos ou 'patrão, o trem atrasou'. In: Contradições Urbanas e Movimentos Sociais (Centro de Estudos de Cultura Contemporânea, org.), pp. 3-65, Rio de Janeiro: Centro de Estudos de Cultura Contemporânea/Paz e Terra.

NEUMAN, J. H. \& BARON, R. A., 1998. Workplace violence and workplace aggression: Evidence concerning specific forms, potential causes, and preferred targets. Journal of Management, 24:391.

NIOSH (National Institute for Occupational Safety and Health)/CIB (Current Intelligence Bulletin), 1996. Violence in the Workplace. Cincinnati: Department of Health and Human Services.

PAES-MACHADO, E. \& LEVENSTEIN, C., 2000. Quando a violência chega ao local de trabalho: Criminalidade violenta e vitimização no transporte coletivo. In: A Outra Face da Moeda; Violência na Bahia (N. Oliveira, L. M. S. Ribeiro \& J. C. Zanetti, org.), pp. 44-68. Salvador: Comissão de Justiça e Paz da Arquidiocese de Salvador.
PAES-MACHADO, E. \& TAPPARELLI, G., 1996. Violência juvenil, infração e morte nas quadrilhas de Salvador. Cadernos do CEAS, 165:63-81.

PAES-MACHADO, E., \& TAPPARELLI, G., 1999. Violência, etnia e cor: Um estudo dos diferenciais na região metropolitana de Salvador, Bahia, Brasil. Pan American Journal of Public Health, 5:268278.

PEGORARO, J. 1999. Inseguridad y violência. In: Violência em Tempo de Globalização (J. V. Tavaresdos-Santos, org.), pp-201-229, São Paulo: Editora Hucitec.

SSP (Secretaria de Segurança Pública)/Policia Civil do Estado da Bahia, 1999. Inquéritos Policiais. Salvador: SSP

SSP (Secretaria de Segurança Pública)/Polícia Militar do Estado da Bahia, 1999. Livros de Fotografias de Assaltantes de Ônibus. Salvador: SSP.

SENNET, R., 1993. O Declínio do Homem Público. São Paulo: Companhia das Letras.

SETEPS (Sindicato das Empresas de Transportes de Salvador), 1998/1999. Relatórios sobre Assaltos de Ônibus. Dados Coletados Através das Fichas das Ocorrências. Salvador: SETEPS.

STTR (Sindicato dos Trabalhadores em Transportes Rodoviários do Estado da Bahia), 1996. Boletim Transporte 7. Salvador: STTR.

SIQUEIRA, M.; MIRANDA, D. F. \& FRÓES, E. S., 1995. Os Ônibus e seus Donos: Relações de Poder no Transporte Coletivo de Belo Horizonte. Belo Horizonte: Centro de Pós-Graduação e Pesquisa, Faculdade de Ciências Econômicas, Universidade Federal de Minas Gerais.

SCOTT, J., 1990. Domination and the Arts of Resistance. Yale: Yale University Press.

SOARES, L. E., 2000. Meu Casaco de General; 500 Dias no Front da Segurança Pública do Rio de Janeiro. São Paulo: Companhia das Letras.

TAVARES-DOS-SANTOS, J. V., 1999. Introdução: Por uma sociologia da conflitualidade no tempo da globalização. In: Violência em Tempo de Globalização (J. V. Tavares-dos-Santos, org.), pp. 11-43, São Paulo: Editora Hucitec.

VASCONCELOS, L., 1999. Grande desafio é enfrentar o atraso. A Tarde, Salvador, 29 mar., Caderno Especial, p. 31.

WRIGHT, R. T. \& DECKER, S. H., 1997. Armed Robbers in Action. Boston: Northeastern University Press.

Recebido em 6 de julho de 2000

Versão final reapresentada em 27 de julho de 2001

Aprovado em 18 de janeiro de 2002 